\title{
Global dynamic spatiotemporal pattern of seasonal influenza since 2009 influenza pandemic
}

\author{
Zhi-Wei $\mathrm{Xu}^{1,2,3}$, Zhong-Jie $\mathrm{Li}^{4}$ and Wen-Biao Hu${ }^{1,2^{*}}$
}

\begin{abstract}
Background: Understanding the global spatiotemporal pattern of seasonal influenza is essential for influenza control and prevention. Available data on the updated global spatiotemporal pattern of seasonal influenza are scarce. This study aimed to assess the spatiotemporal pattern of seasonal influenza after the 2009 influenza pandemic.
\end{abstract}

Methods: Weekly influenza surveillance data in 86 countries from 2010 to 2017 were obtained from FluNet. First, the proportion of influenza $A$ in total influenza viruses $\left(P_{A}\right)$ was calculated. Second, weekly numbers of influenza positive virus ( $A$ and $B$ ) were divided by the total number of samples processed to get weekly positive rates of influenza $A\left(R W_{A}\right)$ and influenza $B\left(R W_{B}\right)$. Third, the average positive rates of influenza $A\left(R_{A}\right)$ and influenza $B\left(R_{B}\right)$ for each country were calculated by averaging $R W_{A}$, and $R W_{B}$ of 52 weeks. A Kruskal-Wallis test was conducted to examine if the year-to-year change in $P_{A}$ in all countries were significant, and a universal kriging method with linear semivariogram model was used to extrapolate $R_{A}$ and $R_{B}$ in all countries.

Results: $P_{A}$ ranged from 0.43 in Zambia to 0.98 in Belarus, and $P_{A}$ in countries with higher income was greater than those countries with lower income. The spatial patterns of high $R_{B}$ were the highest in sub-Saharan Africa, Asia-Pacific region and South America. RW $\mathrm{W}_{\mathrm{A}}$ peaked in early weeks in temperate countries, and the peak of RW $\mathrm{B}$ occurred a bit later. There were some temperate countries with non-distinct influenza seasonality (e.g., Mauritius and Maldives) and some tropical/subtropical countries with distinct influenza seasonality (e.g., Chile and South Africa).

Conclusions: Influenza seasonality is not predictable in some temperate countries, and it is distinct in Chile, Argentina and South Africa, implying that the optimal timing for influenza vaccination needs to be chosen with caution in these unpredictable countries.

Keywords: Influenza a, Influenza B, Seasonality, Spatial pattern, Vaccination

\section{Background}

Seasonal influenza caused substantial morbidity and mortality worldwide, especially in elderly population and children aged under five years. It is estimated that, from 1999 to 2015 , there were 291243 to 645832 seasonal influenzaassociated respiratory deaths every year globally [1], causing a considerable health burden. For example, Australia

\footnotetext{
* Correspondence: w2.hu@qut.edu.au

${ }^{1}$ School of Public Health and Social Work \& Institute of Health and Biomedical Innovation, Queensland University of Technology, Brisbane, Australia

${ }^{2}$ Institute of Health and Biomedical Innovation, Queensland University of Technology, Brisbane, Australia

Full list of author information is available at the end of the article
}

witnessed its largest influenza season in 2017 since the 2009 pandemic, posing a substantial burden to primary care and hospitals [2]. Unveiling the global spatial pattern of seasonal influenza is essential for national and international decision making on influenza prevention and control.

Vaccination has been widely recognized as the most effective means of seasonal influenza prevention and can largely ease the burden caused by influenza. Identification of the optimal timing for vaccination is of great importance because vaccine-induced immunity wanes quickly after vaccination [3], and unfolding influenza seasonality is a crucial step for determining optimal 
vaccination timing. The widespread consensus in the literature is that influenza seasonality pattern is more ascertained in temperate regions/countries, but remains largely unclear and controversial in tropical and subtropical regions/countries [4-6]. It has been suggested that although influenza seasonality in tropics and subtropics is complicated, it might still be possible to group countries into similar zones for tailored and timely vaccination [7].

Prior studies have reported that the epidemiology (e.g., seasonality) of influenza A and influenza B may differ from each other [8-10], and the relative importance of influenza A and influenza B in driving seasonal influenza peak may vary across different countries [11]. For the development of strategic seasonal influenza control programs (e.g., using trivalent vaccines or quadrivalent vaccines), it is essential to assess the proportions of influenza A virus and influenza B virus in seasonal influenza virus.

Global, contemporaneous and comparative analysis of influenza data would help focus resources more effectively on areas/populations that need it most [12, 13]. Previous studies have reported the global spatial and temporal patterns of seasonal influenza up to 2015 [8, 14, 15], but very up-to-date information is not available in existing literature. Our study attempted to characterize the global spatial pattern of seasonal influenza A and B after 2009 influenza pandemic (i.e., from 2010 to 2017), to assess the proportions of influenza A virus and influenza B virus in total influenza virus, and to elucidate the seasonality of seasonal influenza A and B in temperate countries and tropical/subtropical countries. The specific objectives were three-fold: I). what was the proportion of influenza $A$ virus in total influenza positive virus $\left(\mathrm{P}_{\mathrm{A}}\right)$ in each country; and whether there were any year-toyear changes in this proportion? II). what were the high risk regions of influenza $A$ and influenza $B$ ? and III). what were the global seasonal patterns of influenza $\mathrm{A}$ and influenza $\mathrm{B}$ ?

\section{Methods}

\section{Data collection}

Weekly influenza surveillance data from 2010 to 2017 were collected from FluNet, an online database of WHO Global Influenza Surveillance Network for laboratory-confirmed influenza samples $[6,8]$. Detailed information on FluNet can be found in WHO website (http://www.who.int/influenza/gisrs_laboratory/flunet/en/). FluNet data are real-life data. The diagnostic methods may vary widely between countries because of manpower and training issues, but FluNet data are the most widely available data that can be used by WHO surveillance to design the seasonal influenza vaccines. It is not easy practically (if not impossible) to unify the world's approach to testing for these influenza viruses due to the resource variability and limitations. Thus, FluNet data are still quite valuable despite its limitations. Specifically, the data extracted in this study included the following variables: total number of influenza positive virus, total number of influenza A virus, total number of influenza $B$ virus, and total number of samples processed. Countries with complete data of at least one year from 2010 to 2017 were selected, and in total there were 86 countries included in this study. The detailed influenza information on the countries selected, including time period(s), total number of samples processed, total number of influenza positive virus, total number of influenza A virus, and total number of influenza B virus, is depicted in Additional file 1: Table S1. World Bank categorized all countries into four income groups, including low income, lower middle income, upper middle income, and high income. We collected this information for each included country to assess if $\mathrm{P}_{\mathrm{A}}$ varied across different income groups (http://blogs. worldbank.org/opendata/new-country-classificationsincome-level-2017-2018).

\section{Data analysis}

There were three analytical approaches corresponding to three objectives. First, for each country, total number of influenza A virus was divided by total number of influenza positive virus to get the proportion of influenza A virus in total influenza positive virus $\left(\mathrm{P}_{\mathrm{A}}\right)$. Data on 21 countries with complete data from 2010 to 2017 were used to present the year-to-year change in $\mathrm{P}_{\mathrm{A}}$. The yearly $\mathrm{P}_{\mathrm{A}}$ data for each country were ratio and were not normally distributed (after normality test), so we conducted a Kruskal-Wallis test to check if the year-to-year changes in $\mathrm{P}_{\mathrm{A}}$ in all countries were statistically significant. Second, weekly numbers of influenza positive virus for influenza A and influenza B, as well as total number of samples processed, across all years were merged into 52 weeks in each country. Weekly numbers of influenza positive virus (influenza A and influenza B) were divided by the total number of samples processed to get weekly positive rates of influenza $A\left(R W_{A}\right)$, and influenza $B$ $\left(R W_{B}\right)$. The average positive rates of influenza $A\left(R_{A}\right)$, and influenza $B\left(R_{B}\right)$ for each country were calculated by averaging $R W_{A}$, and $R W_{B}$ of 52 weeks, and a kriging approach was used to extrapolate the average influenza positive rate in all countries globally. Specifically, we used the "universal" kriging method and the "linear" semivariogram model. Universal kriging is a powerful method which simultaneously estimates a trend and used the resulting errors for kriging. The equations for calculating $\mathrm{P}_{\mathrm{A}}, \mathrm{RW}_{\mathrm{A}}, \mathrm{RW} \mathrm{W}_{\mathrm{B}}, \mathrm{R}_{\mathrm{A}}$ and $\mathrm{R}_{\mathrm{B}}$, are presented in Table 1. Third, heat maps were plotted using $\mathrm{RW}_{\mathrm{A}}$ and $R W_{B}$ to present the seasonal patterns of influenza $A$ and 
Table 1 The equations for calculating the indexes

\begin{tabular}{|c|c|c|}
\hline Index & Definition of the index & Equation to calculate the index \\
\hline$P_{A}$ & $\begin{array}{l}\text { the proportion of influenza A virus in total influenza } \\
\text { positive virus }\end{array}$ & (total number of influenza A virus) / (total number of influenza positive virus) \\
\hline $\mathrm{RW}_{\mathrm{A}}$ & weekly positive rate of influenza $A$ & $\begin{array}{l}\text { (weekly number of influenza A positive virus) / (total number of samples } \\
\text { processed) }\end{array}$ \\
\hline $\mathrm{RW}_{\mathrm{B}}$ & weekly positive rate of influenza $B$ & $\begin{array}{l}\text { (weekly number of influenza B positive virus) / (total number of samples } \\
\text { processed) }\end{array}$ \\
\hline $\mathrm{R}_{\mathrm{A}}$ & the average positive rate of influenza A & $\left(\mathrm{RW}_{\text {Aweek1 }}+\mathrm{RW}_{\text {Aweek2 }}+\ldots+\mathrm{RW}_{\text {Aweek } 52}\right) / 52$ \\
\hline$R_{B}$ & the average positive rate of influenza B & $\left(\mathrm{RW}_{\text {Bweek1 }}+\mathrm{RW}_{\text {Bweek2 }}+\ldots+\mathrm{RW}_{\text {Bweek52 }}\right) / 52$ \\
\hline
\end{tabular}

influenza B in temperate countries and tropical/subtropical countries. A cosinor function combined with Poisson regression was used to quantify the peak time and trough time of influenza A and influenza B [16].

Spatial mapping and kriging were conducted in ArcGIS 10.5 (ESRI Inc., Redlands, CA, USA), and all other analyses were done in $\mathrm{R}$ package 3.4.4 (https:// www.r-project.org/).

\section{Results}

The global spatial pattern of $\mathrm{P}_{\mathrm{A}}$ and its temporal change The proportion of influenza A virus in total influenza positive virus $\left(\mathrm{P}_{\mathrm{A}}\right)$ were illustrated in Fig. 1. The highest $\mathrm{P}_{\mathrm{A}}$ was in Belarus (upper-middle-income), Ethiopia (low-income), Iraq (upper-middle-income), and Venezuela (upper-middle-income). Specifically, $\mathrm{P}_{\mathrm{A}}$ was greater than 0.5 in all countries except for Zambia and Lebanon. Fig. 2 shows that $\mathrm{P}_{\mathrm{A}}$ was higher in high-income and upper-middle-income countries than low-income and lower-middle-income countries $(P=0.0015$ in the Kruskal-Wallis test), although one of the four countries with the highest $\mathrm{P}_{\mathrm{A}}$ was a lowincome country (i.e., Ethiopia). Fig. 3 shows that there were year-to-year changes in the relative proportions of influenza A virus. The Kruskal-Wallis test indicates that the year-toyear changes globally were not statistically significant $(P=$ $0.5271)$.

\section{The global spatial patterns of $R_{A}$ and $R_{B}$}

The global spatial patterns of $R_{A}$ and $R_{B}$ was shown in Fig. 4. The highest $\mathrm{R}_{\mathrm{A}}$ distributed in Venezuela, Bolivia, Nepal, Ethiopia and China, and the highest $R_{B}$ distributed in sub-Saharan Africa, Asia-Pacific region and South America.

\section{The seasonal patterns of influenza a and influenza B}

The seasonal patterns of $R W_{A}$ and $R W_{B}$ in temperate countries and tropical/subtropical countries by latitude were presented in Fig. 5. $R W_{A}$ and $R W_{B}$ peaked in early weeks of each year in most temperate countries except for Australia, New Caledonia, Mauritius, Maldives and Malaysia, and the peak weeks of $\mathrm{RW}_{\mathrm{A}}$ occurred earlier than influenza $\mathrm{RW}_{\mathrm{B}}$. For most tropical/subtropical countries, influenza seasonality pattern was diverse (i.e., either having several peaks or occurring all year around).

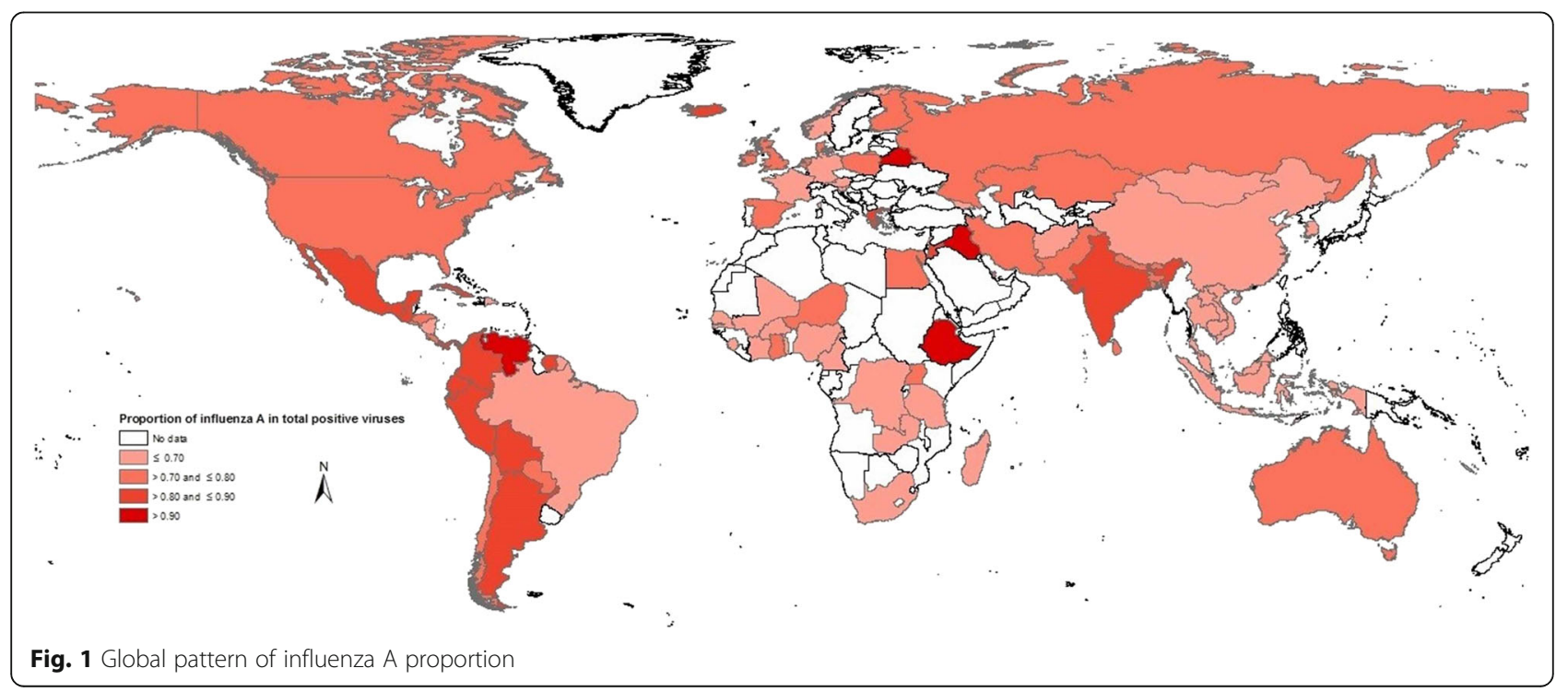




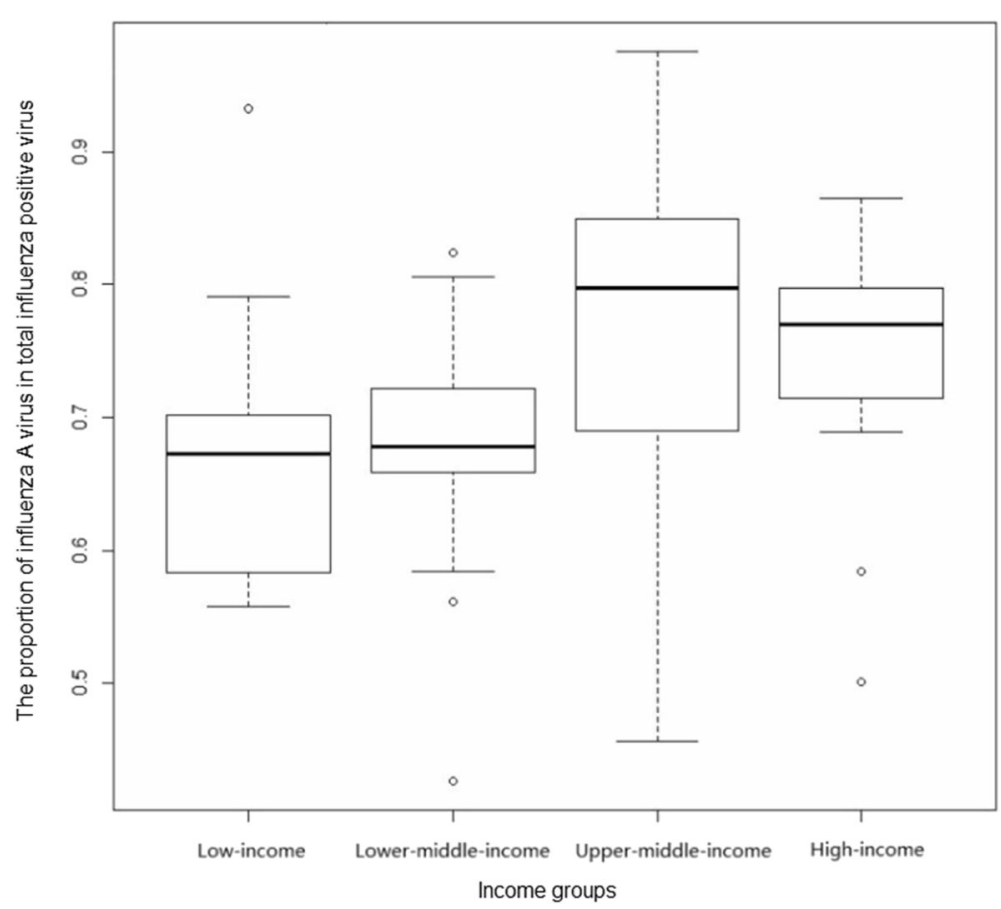

Fig. 2 Influenza A proportion in countries from different income groups

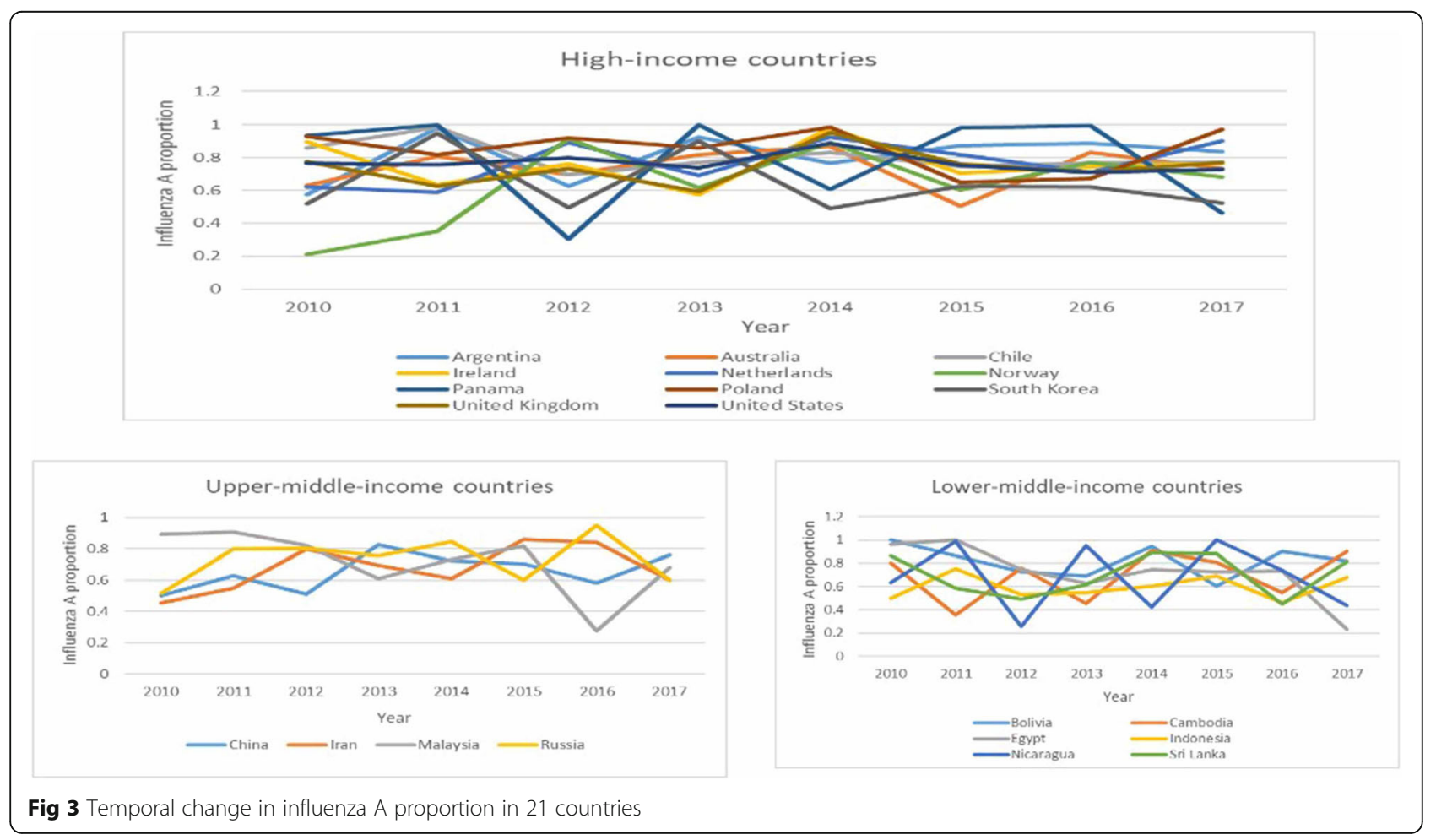




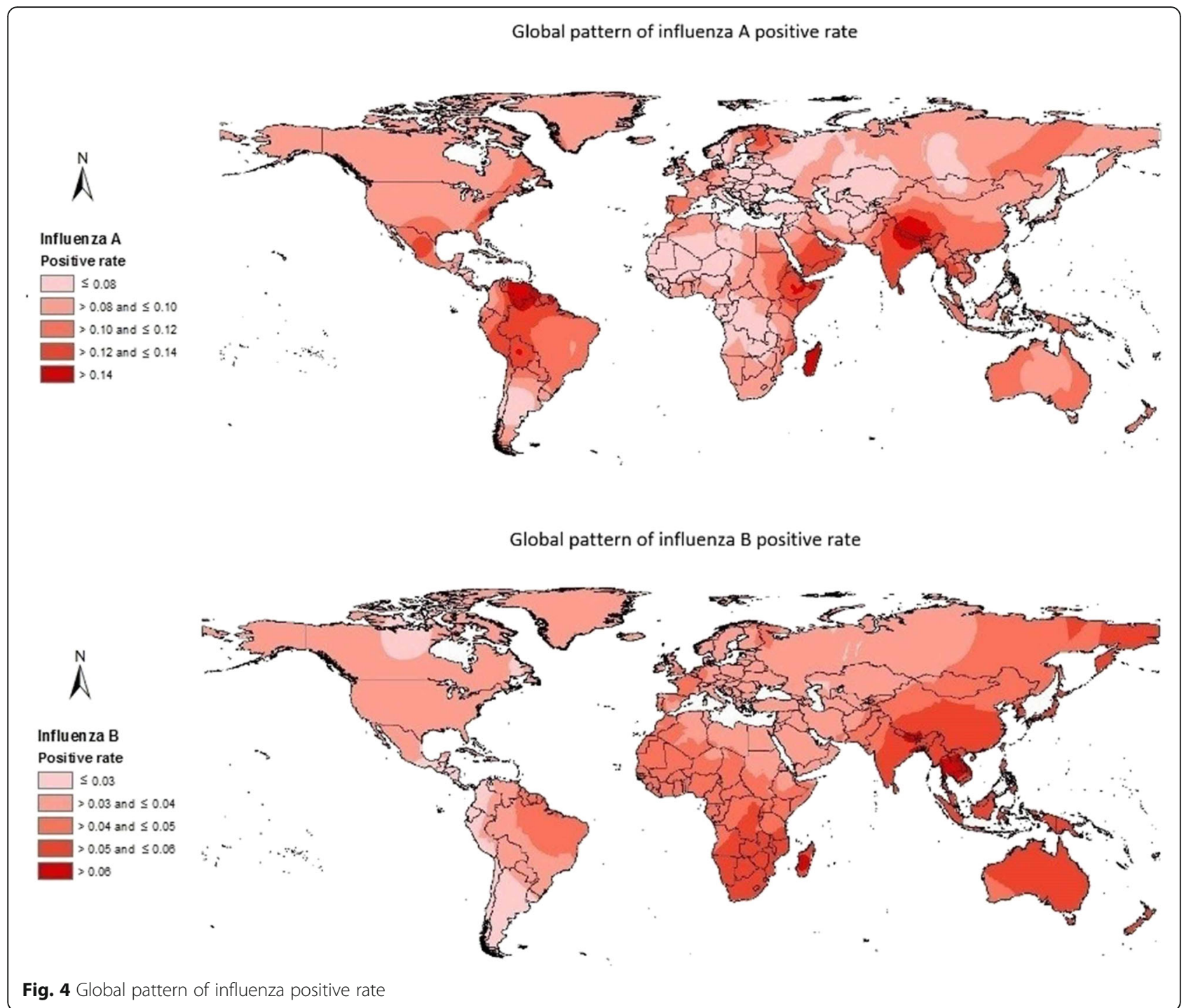

However, influenza seasonality was distinct in Chile, Argentina, and South Africa. The peak time and trough time of influenza in all selected countries quantified by cosinor function are presented in Table 2 . The peak time and trough time varied considerably across different countries.

The seasonal patterns of $\mathrm{RW}_{\mathrm{A}}$ and $\mathrm{RW}_{\mathrm{B}}$ in 21 countries with complete data from 2010 to 2017 were shown in Additional file 2: Figure S1. Influenza seasonality in the two tropical/subtropical countries, i.e., Chile and Argentina, was steadily distinct across different years.

\section{Discussion}

This study used data up to 2017 and kriging approach to unravel the updated global spatial pattern of seasonal influenza. It quantified the proportion of influenza A virus in total influenza virus and modeled the peak times of influenza A and influenza B in each country from 2010 to 2017. Three findings are note-worthy. First, the highest $\mathrm{P}_{\mathrm{A}}$ was observed in Belarus, Ethiopia, Iraq, and Venezuela, and $\mathrm{P}_{\mathrm{A}}$ changed from year to year. Second, for influenza $B$, high risk regions distributed in subSaharan Africa, Asia-Pacific region and South America. Third, influenza seasonality was distinct in most temperate countries but there were some exceptions (e.g., Mauritius and Maldives), and influenza seasonality was surprisingly distinct in some tropical/subtropical countries, including Chile, Argentina and South Africa.

Unsurprisingly, we observed that influenza A was the dominant subtype in almost all countries (except for Zambia and Lebanon). Notwithstanding, we found that the proportion of influenza $B$ was greater than the proportion of influenza A in certain years in Malaysia, Nicaragua, Panama, Egypt, and Norway. Iuliano et al. estimated the global burden of influenza-associated respiratory deaths and reported that the highest mortality 


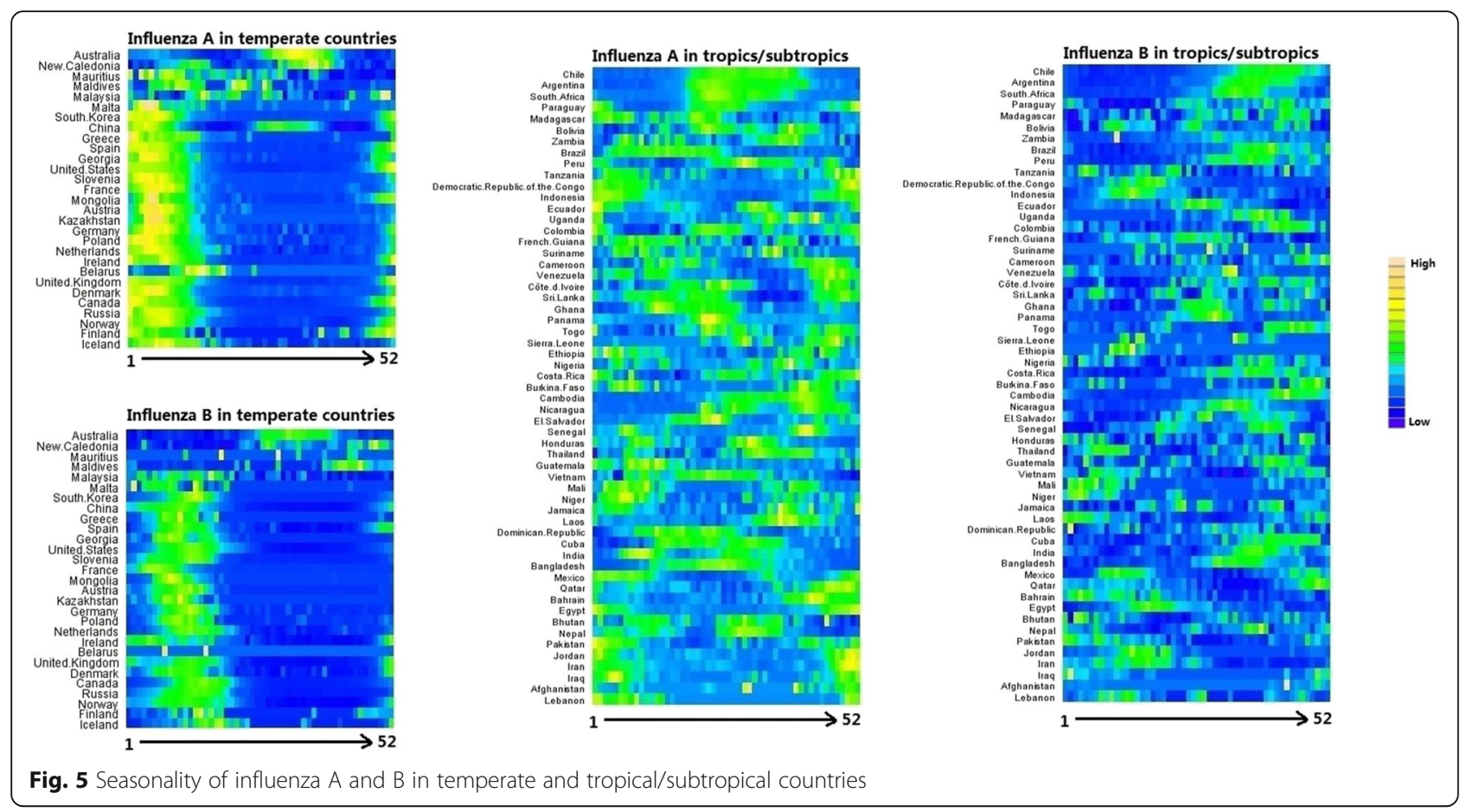

rate was found in sub-Saharan Africa and southeast Asia, and among those who are aged 75 years or older [1]. The high positive rate of influenza $B$ that we observed in sub-Saharan Africa suggested that not only mortality but also morbidity in this region were high, calling for more influenza prevention resources to be allocated to this socioeconomically-disadvantaged region. Previous studies have also highlighted the necessity of building comprehensive influenza surveillance system in sub-Saharan Africa [17-19]. Regarding the influenza situation in Asia-Pacific region, some countries such as Australia and China had a high influenza positive rate (finding of the present study) but low/moderate mortality rate [1], implying a relatively good healthcare system in these countries but also suggesting a strong need to identify the national, regional, and local optimal vaccination timing for cost-effective influenza prevention (especially for China as it has wide latitude spans) [10], and to build up influenza early warning system which gives warning in a timely manner (e.g., internet-based early warning tools incorporating information collected through traditional surveillance system) [20]. Our prior works have suggested that early warning of infectious diseases using data from search engine (e.g., Google and Baidu) may shed some new light on infectious disease control [21, 22]. The constrains and barriers for influenza control and prevention in Asia-Pacific region are multifaceted (e.g., logistic and resourcing issues) [23], and preventing people in this region from influenza attacks requires concerted efforts from policy makers, public health officials, healthcare workers, and scientists.

The noticeable change of influenza seasonality in the included countries that we observed in this study, to some extent, indicates that there is no one-size-suits-all vaccination timing for tropical/subtropical countries and some temperate countries. Grouping tropical/subtropical countries into several zones for influenza vaccination might need much more detailed works (e.g., identifying the fundamental determinants behind the year-to-year change in seasonality etc.). A prior study investigating the global environmental drivers found that absolute humidity and temperature drive the outbreaks of seasonal influenza [24], and the season of influenza in Vietnam has been found coinciding with the rainy seasons [4], implying that future endeavors aiming to look at the relationships between climatic factors and influenza season in a regional or local scale in tropical and subtropical countries are warranted.

This study has two strengths. First, it unfolded the global spatial pattern of influenza positive rate, which may aid policy making in influenza control and prevention. Second, it identified some temperate countries with non-distinct influenza seasonality and some tropical/ subtropical countries with distinct influenza seasonality. Five limitations of this study need to be acknowledged. First, there was sampling bias due to overall bias of case data being reported between different countries. Second, the time periods for all selected countries were not consistent, although they were all within the range of 2010 
Table 2 Peak time and trough time (week) of influenza (listed by latitude)

\begin{tabular}{|c|c|c|c|c|}
\hline Country & Peak $\left(A^{a}\right)$ & Trough (A) & Peak $\left(B^{a}\right)$ & Trough (B) \\
\hline Chile & 30.5 & 4.5 & 40.5 & 14.5 \\
\hline Argentina & 29.3 & 3.3 & 37.6 & 11.6 \\
\hline South Africa & 27.9 & 1.9 & 35.3 & 9.3 \\
\hline Australia & 33.8 & 7.8 & 33.7 & 7.7 \\
\hline Paraguay & 36.7 & 10.7 & 39.6 & 13.6 \\
\hline New Caledonia & 33.4 & 7.4 & 40.9 & 14.9 \\
\hline Mauritius & 12.4 & 38.4 & 28.3 & 2.3 \\
\hline Madagascar & 13.4 & 39.4 & 37.3 & 11.3 \\
\hline Bolivia & 30.8 & 4.8 & 21.8 & 47.8 \\
\hline Zambia & 31.8 & 5.8 & 32.3 & 6.3 \\
\hline Brazil & 15.2 & 41.2 & 40 & 14 \\
\hline Peru & 34.3 & 8.3 & 37.4 & 11.4 \\
\hline Tanzania & 51.8 & 26.8 & 8.2 & 34.2 \\
\hline Indonesia & 2.4 & 28.4 & 15.9 & 41.9 \\
\hline Ecuador & 2.6 & 28.6 & 24.8 & 50.8 \\
\hline $\begin{array}{l}\text { Democratic } \\
\text { Republic of the Congo }\end{array}$ & 2.6 & 28.6 & 15.4 & 41.4 \\
\hline Uganda & 40.3 & 14.3 & 37.6 & 11.6 \\
\hline Maldives & 16.3 & 42.3 & 44.1 & 18.1 \\
\hline Malaysia & 13.4 & 39.4 & 12.8 & 38.8 \\
\hline Colombia & 33 & 7 & 45.3 & 19.3 \\
\hline French Guiana & 9.2 & 35.2 & 22.8 & 48.8 \\
\hline Suriname & 28.4 & 2.4 & 30.7 & 4.7 \\
\hline Cameroon & 50.4 & 24.4 & 44.1 & 18.1 \\
\hline Venezuela & 1.9 & 27.9 & 32.3 & 6.3 \\
\hline Côte d'Ivoire & 25.1 & 51.1 & 37.8 & 11.8 \\
\hline Sri Lanka & 10 & 36 & 4.7 & 30.7 \\
\hline Ghana & 18.7 & 44.7 & 34.8 & 8.8 \\
\hline Panama & 24.2 & 50.2 & 28.5 & 2.5 \\
\hline Togo & 34 & 8 & 46.7 & 20.7 \\
\hline Sierra Leone & 40 & 14 & 25.4 & 51.4 \\
\hline Ethiopia & 52.9 & 26.9 & 12.8 & 38.8 \\
\hline Nigeria & 39 & 13 & 47 & 21 \\
\hline Costa Rica & 45 & 19 & 37.4 & 11.4 \\
\hline Burkina Faso & 51.7 & 25.7 & 50 & 24 \\
\hline Cambodia & 37 & 11 & 42.9 & 16.9 \\
\hline Nicaragua & 36.9 & 10.9 & 33.4 & 7.4 \\
\hline El Salvador & 22.9 & 48.9 & 34.2 & 8.2 \\
\hline Senegal & 47.4 & 21.4 & 31.1 & 5.1 \\
\hline Honduras & 24.8 & 50.8 & 51.7 & 25.7 \\
\hline Thailand & 37.4 & 11.4 & 5.6 & 31.6 \\
\hline Guatemala & 9.4 & 35.4 & 40.8 & 14.8 \\
\hline Vietnam & 22.7 & 48.7 & 4.9 & 30.9 \\
\hline Mali & 3 & 29 & 4.3 & 30.3 \\
\hline Niger & 2.8 & 28.8 & 5.4 & 31.4 \\
\hline
\end{tabular}

Table 2 Peak time and trough time (week) of influenza (listed by latitude) (Continued)

\begin{tabular}{|c|c|c|c|c|}
\hline Country & Peak $\left(A^{a}\right)$ & Trough (A) & Peak $\left(B^{a}\right)$ & Trough (B) \\
\hline Jamaica & 47.1 & 21.1 & 31 & 5 \\
\hline Laos & 38.8 & 12.8 & 2.1 & 28.1 \\
\hline Deminican Republic & 18.2 & 44.2 & 31 & 5 \\
\hline Cuba & 25.4 & 51.4 & 40.8 & 14.8 \\
\hline India & 17.5 & 43.5 & 39.9 & 13.9 \\
\hline Bangladesh & 25.3 & 51.3 & 34.7 & 8.7 \\
\hline Mexico & 2.1 & 28.1 & 6.8 & 32.8 \\
\hline Qatar & 49.6 & 23.6 & 4.6 & 30.6 \\
\hline Bahrain & 45.2 & 19.2 & 10.1 & 36.1 \\
\hline Egypt & 51.1 & 25.1 & 19.8 & 45.8 \\
\hline Bhutan & 24.8 & 50.8 & 51.4 & 25.4 \\
\hline Nepal & 26.7 & 52.7 & 41.1 & 15.1 \\
\hline Pakistan & 51.6 & 25.6 & 5.5 & 31.5 \\
\hline Jordan & 52.7 & 26.7 & 14.9 & 40.9 \\
\hline Iran & 1 & 27 & 14.3 & 40.3 \\
\hline Iraq & 1.6 & 27.6 & 2.7 & 28.7 \\
\hline Afghanistan & 43.4 & 17.4 & 46.3 & 20.3 \\
\hline Lebanon & 4.4 & 30.4 & 9.7 & 35.7 \\
\hline Malta & 5.7 & 31.7 & 8.7 & 34.7 \\
\hline South Korea & 4.8 & 30.8 & 12.1 & 38.1 \\
\hline China & 4.2 & 30.2 & 8.4 & 34.4 \\
\hline Greece & 7.1 & 33.1 & 10.5 & 36.5 \\
\hline Spain & 4.1 & 30.1 & 9.1 & 35.1 \\
\hline Georgia & 5.7 & 31.7 & 10.8 & 36.8 \\
\hline United States & 4.1 & 30.1 & 12.2 & 38.2 \\
\hline Slovenia & 5.9 & 31.9 & 10.7 & 36.7 \\
\hline France & 6.2 & 32.2 & 7.2 & 33.2 \\
\hline Mongolia & 4.5 & 30.5 & 10 & 36 \\
\hline Austria & 7 & 33 & 10.8 & 36.8 \\
\hline Kazakhstan & 6.5 & 32.5 & 9.6 & 35.6 \\
\hline Germany & 6.7 & 32.7 & 12.2 & 38.2 \\
\hline Poland & 6 & 32 & 10.7 & 36.7 \\
\hline Netherlands & 6.7 & 32.7 & 12.7 & 38.7 \\
\hline Ireland & 5.8 & 31.8 & 8 & 34 \\
\hline Belarus & 14.3 & 40.3 & 12.4 & 38.4 \\
\hline United Kingdom & 5.4 & 31.4 & 9.1 & 35.1 \\
\hline Denmark & 5.4 & 31.4 & 9.3 & 35.3 \\
\hline Canada & 4 & 30 & 14 & 40 \\
\hline Russia & 7.2 & 33.2 & 12.6 & 38.6 \\
\hline Norway & 5.8 & 31.8 & 11.2 & 37.2 \\
\hline Finland & 52.8 & 26.8 & 9.5 & 35.5 \\
\hline Iceland & 8.3 & 34.3 & 15.4 & 41.4 \\
\hline
\end{tabular}

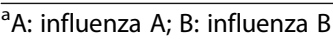


to 2017. It would benefit the influenza surveillance a lot if some countries with data covering a short period of time (e.g., Mauritius) had more resources injection. Third, the country-level data restricted us to explore the socioecological drivers of influenza seasonality. Fourth, different subtypes of influenza A have different and complex transmission routes, and the results of this study only present a global figure on all influenza A subtypes. Fifth, there were large amount of missing data on the subtypes of influenza A in the FluNet data, which restricted us to distinguish and study the patterns of different influenza viruses.

\section{Conclusions}

Influenza control and prevention attention can predominantly be paid to influenza $\mathrm{A}$ in countries such as Venezuela. Sub-Saharan Africa needs more influenza control resources, and efficient influenza prevention programs in Asia-Pacific region call for state-of-the-art internet-based influenza early warning system incorporating traditional surveillance data. Future attempts using spatiotemporal approaches to explore the drivers (e.g., socio-ecological factors) behind the influenza seasonality of tropical and subtropical countries are warranted.

\section{Supplementary information}

Supplementary information accompanies this paper at https://doi.org/10. 1186/s40249-019-0618-5.

Additional file 1: Table S1. Detailed information on influenza in the selected countries (listed by latitude).

Additional file 2: Figure S1. Seasonality patterns of influenza $A$ and influenza B in countries of temperate climate and of tropical or subtropical climate, from 2010 to 2017

\section{Abbreviations}

$P_{A}$ : The proportion of influenza A virus in total influenza positive virus:" $R_{A}$ : The average positive rate of influenza $A_{;} R_{B}$ : The average positive rate of influenza $B ; W_{A}$ : Weekly positive rate of influenza $A ; R W_{B}$ : Weekly positive rate of influenza $B$

\section{Acknowledgements}

We'd like to thank World Health Organization for making the FluNet data publicly available. Dr. Wenbiao Hu was supported by an Australian Research Council Future Fellowship (award number FT140101216).

\section{Authors' contributions}

WH conceived the study. ZX and WH analyzed the data. ZX drafted the manuscript. $W H, Z X$ and $Z L$ interpreted the results and revised the manuscript. All authors read the approved the final manuscript.

\section{Funding}

No funding.

\section{Availability of data and materials}

The data used in this study are publicly available data, and can be accessed from WHO FluNet (https://www.who.int/influenza/gisrs_laboratory/flunet/en/).

Ethics approval and consent to participate

Not applicable.
Consent for publication

Not applicable.

\section{Competing interests}

The authors declare that they have no competing interests.

\section{Author details}

${ }^{1}$ School of Public Health and Social Work \& Institute of Health and Biomedical Innovation, Queensland University of Technology, Brisbane, Australia. ${ }^{2}$ Institute of Health and Biomedical Innovation, Queensland University of Technology, Brisbane, Australia. ${ }^{3}$ School of Public Health, Faculty of Medicine, University of Queensland, Brisbane, Australia. ${ }^{4}$ Division of Infectious Disease, Key Laboratory of Surveillance and Early-warning on Infectious Disease, Chinese Center for Disease Control and Prevention, Beijing, China.

Received: 24 September 2019 Accepted: 18 December 2019

Published online: 03 January 2020

\section{References}

1. Iuliano AD, Roguski KM, Chang HH, Muscatello DJ, Palekar R, Tempia S, et al. Estimates of global seasonal influenza-associated respiratory mortality: a modelling study. Lancet. 2017;391(10127):1285-300.

2. Australian Government Department of Health: 2017 influenza season in Australia: A summary from the National Influenza Surveillance Committee. 2017.

3. Castilla J, Martínez-Baz I, Martínez-Artola V, Reina G, Pozo F, García Cenoz M, et al. Decline in influenza vaccine effectiveness with time after vaccination, Navarre, Spain, season 2011/12. Eurosurveillance. 2013;18(5):20388.

4. Caini S, Andrade W, Badur S, Balmaseda A, Barakat A, Bella A, et al. Temporal patterns of influenza a and $B$ in tropical and temperate countries: what are the lessons for influenza vaccination? PLoS One. 2016;11(3):e0152310.

5. Tamerius J, Nelson MI, Zhou SZ, Viboud C, Miller MA, Alonso WJ. Global influenza seasonality: reconciling patterns across temperate and tropical regions. Environ Health Perspect. 2011;119(4):439-45.

6. Newman LP, Bhat N, Fleming JA, Neuzil KM. Global influenza seasonality to inform country-level vaccine programs: an analysis of WHO FluNet influenza surveillance data between 2011 and 2016. PLoS One. 2018;13(2):e0193263.

7. Hirve S, Newman LP, Paget J, Azziz-Baumgartner E, Fitzner J, Bhat N, et al. Influenza seasonality in the tropics and subtropics - when to vaccinate? PLoS One. 2016;11(4):e0153003.

8. He D, Lui R, Wang L, Tse CK, Yang L, Stone L. Global spatio-temporal patterns of influenza in the post-pandemic era. Sci Rep. 2015;5:11013.

9. Iha Y, Kinjo T, Parrott G, Higa F, Mori H, Fujita J. Comparative epidemiology of influenza $A$ and $B$ viral infection in a subtropical region: a 7-year surveillance in Okinawa, Japan. BMC Infect Dis. 2016;16:650.

10. Yu H, Alonso WJ, Feng L, Tan Y, Shu Y, Yang W, et al. Characterization of regional influenza seasonality patterns in China and implications for vaccination strategies: spatio-temporal modeling of surveillance data. PLoS Med. 2013;10(11):e1001552.

11. Saha S, Chadha M, Mamun AA, Rahman M, Sturm-Ramirez K, Chittaganpitch $M$, et al. Influenza seasonality and vaccination timing in tropical and subtropical areas of southern and South-Eastern Asia. Bull World Health Organ. 2014;92(5):318-30.

12. Lam TT, Tang JW, Lai FY, Zaraket H, Dbaibo G, Bialasiewicz S, et al. Comparative global epidemiology of influenza, respiratory syncytial and parainfluenza viruses, 2010-2015. J Inf Secur. 2019;79(4):373-82.

13. Tang JW, Lam TT, Zaraket H, Lipkin WI, Drews SJ, Hatchette TF, et al. Global epidemiology of non-influenza RNA respiratory viruses: data gaps and a growing need for surveillance. Lancet Infect Dis. 2017;17(10):e320-6.

14. Alonso WJ, Yu C, Viboud C, Richard SA, Schuck-Paim C, Simonsen L, et al. A global map of hemispheric influenza vaccine recommendations based on local patterns of viral circulation. Sci Rep. 2015;5:17214.

15. He D, Chiu APY, Lin Q, Yu D. Spatio-temporal patterns of proportions of influenza B cases. Sci Rep. 2017;7:40085

16. Xu Z, Hu W, Zhang Y, Wang X, Tong S, Zhou M. Spatiotemporal pattern of bacillary dysentery in China from 1990 to 2009: what is the driver behind? PLoS One. 2014;9(8):e104329.

17. McAnerney JM, Cohen C, Moyes J, Besselaar TG, Buys A, Schoub BD, et al. Twenty-five years of outpatient influenza surveillance in South Africa, 19842008. J Infect Dis. 2012;206(suppl_1):S153-8. 
18. Nyatanyi T, Nkunda R, Rukelibuga J, Palekar R, Muhimpundu MA, Kabeja A et al. Influenza sentinel surveillance in Rwanda, 2008-2010. J Infect Dis. 2012;206(suppl_1):S74-9.

19. Theo A, Liwewe M, Ndumba I, Mupila Z, Tambatamba B, Mutemba C, et al. Influenza surveillance in Zambia, 2008-2009. J Infect Dis. 2012; 206(suppl_1):S173-7.

20. Milinovich GJ, Williams GM, Clements ACA, Hu W. Internet-based surveillance systems for monitoring emerging infectious diseases. Lancet Infect Dis. 2014;14(2):160-8.

21. Liu K, Wang T, Yang Z, Huang X, Milinovich GJ, Lu Y, et al. Using Baidu search index to predict dengue outbreak in China. Sci Rep. 2016;6:38040.

22. Zhang Y, Milinovich G, Xu Z, Bambrick H, Mengersen K, Tong S, et al. Monitoring pertussis infections using internet search queries. Sci Rep. 2017; 7(1):10437.

23. Cowling BJ, Caini S, Chotpitayasunondh T, Djauzi S, Gatchalian SR, Huang $\mathrm{QS}$, et al. Influenza in the Asia-Pacific region: findings and recommendations from the global influenza initiative. Vaccine. 2017:35(6):856-64.

24. Deyle ER, Maher MC, Hernandez RD, Basu S, Sugihara G. Global environmental drivers of influenza. Proc Natl Acad Sci U S A. 2016;113(46): 13081-6.

Ready to submit your research? Choose BMC and benefit from:

- fast, convenient online submission

- thorough peer review by experienced researchers in your field

- rapid publication on acceptance

- support for research data, including large and complex data types

- gold Open Access which fosters wider collaboration and increased citations

- maximum visibility for your research: over $100 \mathrm{M}$ website views per year

At $\mathrm{BMC}$, research is always in progress.

Learn more biomedcentral.com/submissions 